\title{
An Analysis on the Electronic Technology Teaching and the Cultivation of Students' Innovative Ability
}

\author{
Renbo $\mathrm{Xu}^{1,2, \mathrm{a}^{*}}$, Jinfeng $\mathrm{Li}^{1, \mathrm{~b}}$ and Youhui Zou ${ }^{1, \mathrm{c}}$ \\ ${ }^{1}$ School of electrical and information Engineering, Nanchang Institute of Science and \\ Technology Nanchang, 330108, china. \\ ${ }^{2}$ Physics and Microelectronics Institute, Central South University \\ Changsha 410083 china. \\ a 1310079831@qq.com, b524892454@qq.com, ${ }^{\mathrm{c}} 1453939839 @ q q . c o m$
}

Keywords: The automation in the electronic design; Electronic technology; Innovative ability; Ability to analyze problems

\begin{abstract}
At present, the demands for high-quality and innovative talents are becoming stronger and stronger, and the innovative consciousness in cultivating students is becoming the inevitable requirement in teaching. This paper studies some measures to promote the development of students' innovative thinking ability in classroom teaching and practical activities. It is pointed out that using the EDA software can stimulate students' interest in learning knowledge, and can consolidate and deepen the mastery to the theoretical knowledge, and this paper discusses the application of experimental teaching to cultivate the innovative ability of college students, which has a significant meaning.
\end{abstract}

\section{Introduction}

Electronic technology is one of the important, professional and basic courses in the electric major. It is a comprehensive and forward-looking subject with a practical and applied function, and it has a teacher's educational idea, teaching content and teaching method, which directly affects the students' knowledge structure, competency structure and professional skills[1]. How to complete the teaching task and better to develop students' practical ability and to improve the innovative consciousness is a difficult problem placing in education in a relatively short period of time[2]. This paper carries out the education-innovation research and the practice from the aspect of the teaching methods, the teaching means and the experimental teaching to the electronic technology curriculum and explores the main clue of how to apply to the teaching methods and this paper is about how to improve the cultivation ability to organize a teaching activity[3]. This paper cultivates the innovative ability of students by using scientific and effective teaching means and teaching methods and this paper optimizes the teaching contents and cultivates the talents with composite students' innovative ability[4].

\section{Teaching Theory and the use of Multimedia Teaching}

Both the traditional teaching methods and the teaching methods are simple, many teachers feel the hardships of teaching blackboard, it is not easy to stimulate students' interest, resulting in difficult to understand the teaching contents. In order to effectively achieve better teaching results, teachers often in the classroom draw a variety of circuit diagrams, and this process takes up a lot of time in the classroom. Then many concepts in the course are more abstract and difficult for students to understand. Multimedia technology is new form information based on computers, and it combines with the text, pictures, sound, video and other interactive functions. Multimedia teaching has a large amount of classroom information, and it can save teaching time. It has a vivid and intuitive function, and it can achieve the characteristics of virtual experiments in teaching which are widely used[5]. Picture, projection, slide, video, animation and computer-aided teaching (CAI) courseware and other multimedia technologies have entered the classroom, which not only introduces a new technology, but also exerts the teaching and artistic function[6]. There are a large number of 
multimedia-assisted teaching methods, which are new modern teaching methods, which is the best choice with the scientific nature, advanced, vivid and intuitive characteristics as the best choice for teaching. Multimedia teaching methods can improve an amount of classroom teaching information, and the methods can enrich the classroom teaching effect and also can provide a good platform for colleges and universities to improve the teaching quality and efficiency[7].

\section{To Stimulate Interest and Focus on the Experimental Teaching}

It is important to cultivate students' interest in learning electronic technology. Electronic technology is a kind of basic course which is closely related to the experiment. Experimental teaching is an important part in the course of electronic technology[8]. It combines theory with practice, so that students can obtain the sensible knowledge through practical operation, and can stimulate the learning interest and improve the practical ability. Traditional experimental circuit consumes times and efforts, and students make many mistakes inevitably, and even cause damage to components, equipments and other issues. To solve the above practical difficulties, computer-aided teaching has become an important way to realize the modernized education, and it also is an important way to improve students' interest in learning[9]. Various simulation and simulation experiments are carried out by using electronic design automation (EDA) technology, especially for hardware experiments that haven't a condition, which can also be done by using EDA software. Through the modern reaching means by combing "virtual" with "reality", the practical operation and computer simulation can be combined, which can realize the real-time and interactive teaching purposes and can make the experimental teaching methods being the heuristic, visualized, discussing and open direction. In a series of EDA software, the software package Multisim has a great performance advantage, which can simulate and analyze the electrical circuits, digital circuits, analog circuits, radio frequency circuits, automatic control circuit and parts of the computer interface circuits. Through the simulation experiments that are very similar with the actual situation, students are exposed to the experimental process and results, and the vivid image of the simulation also leaves a deep impression to students, so that they combine theory with practice and can improve students' interest in the experimental classes[10].

\section{Specific Implementation Methods}

In order to improve the innovation-design ability and practical ability, and the efficiency of experiment. Designing the mechanism movement program innovation test by the methods of theorist preparation virtual experiments material experiments[10]. Here, we introduce the design case of electronic technology to analyze the relationship between students' practical ability and the design course. 


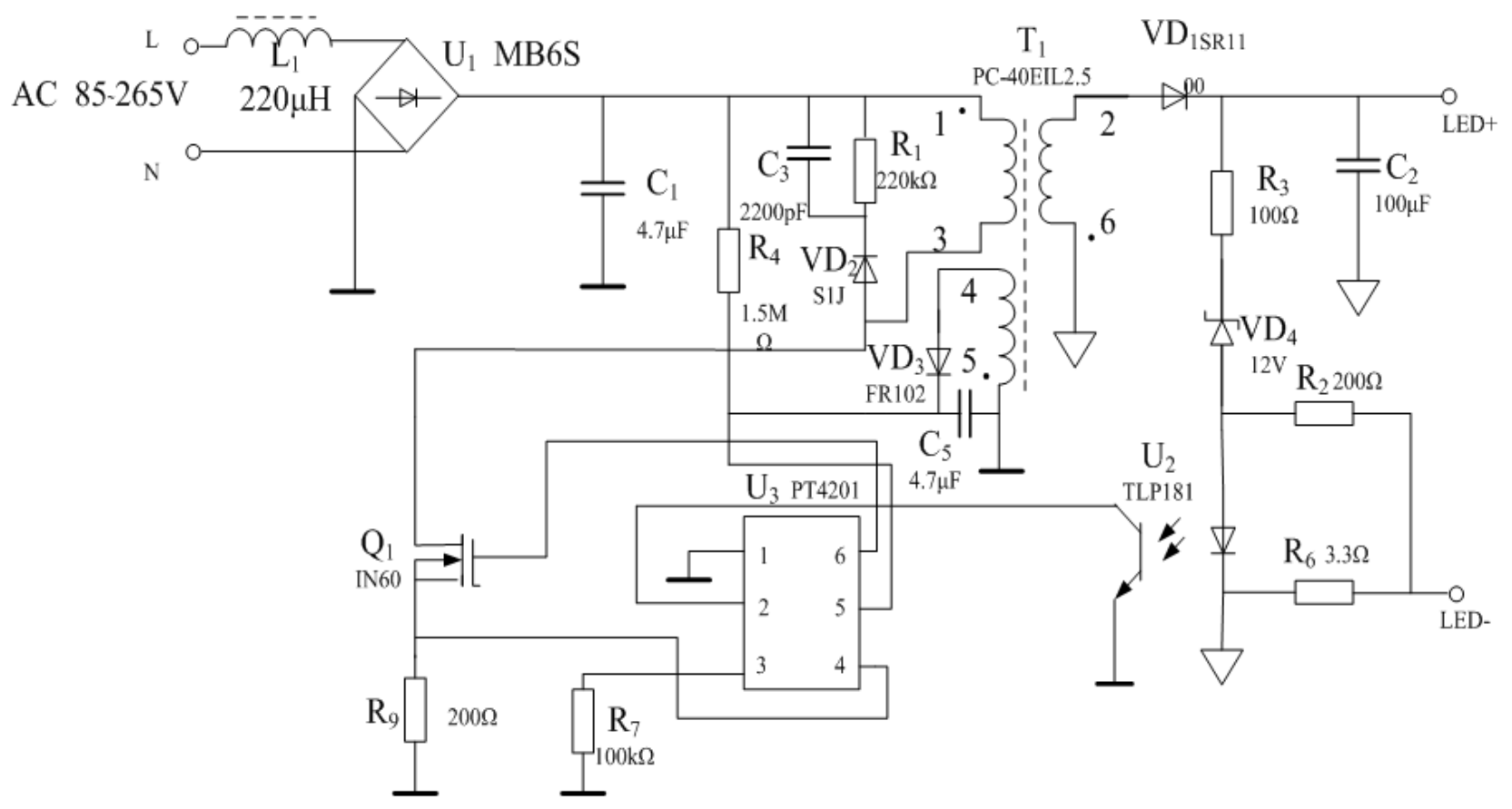

Figure1. Concrete embodiment graphics

Figure1 is a PT4201 based offline semiconductor lighting driver design. The circuit uses flyback topology and uses auxiliary side feedback (i.e. optocoupler feedback to improve the output current accuracy. AC $85 \sim 265 \mathrm{~V}$ AC input, through the L1 (equivalent to a fuse, anti surge), access to the rectifier bridge, the voltage output from the rectifier bridge is about 1.4Vin, current is about $1 \mathrm{~A}$. The $\mathrm{C} 1$ is a filter capacitor. The VDD end of the PT4201 is powered by the R4 voltage regulator, which is powered by the transformer auxiliary winding after starting, and the voltage is between 9 and $27 \mathrm{~V}$. The R1, C3, and VD2 in the circuit are a RCD absorption loop used to absorb spikes generated by the Q1 switches.

Reducing the resistance of R1 can improve the absorption effect, but it will lead to lower system efficiency, and compromise should be adopted in the design. The Rosc (3 pin) of the PT4201 is connected with the resistor R7, which is used to set the switching frequency. The frequency is set to $65 \mathrm{kHz}$ here. The CS (4 PIN) of the PT4201 is connected with the sampling resistor R9 and sets the current.

U2 optocoupler, when the current R6 is large, the current light emitting diode on the photosensitive resistance to change, after induction, the feedback current to PT4201 FB, FB ( 2 feet) voltage decreases, PT4201 by adjusting the duty cycle to reduce the energy, reduces the current on R6. Since the sampling current is fed back to the chip from the output side, such side feedback can fine tune the current in real time, thus improving the accuracy of the output current.

The circuit adopts flyback topology. When the Q1 is switched off, the 5 and 6 terminals of the transformer are connected. When the Q1 is on, the 1 and 2 terminals of the transformer have current, and the 3, 4, 5 and 6 terminals are cut off. Since the sampling current is fed back to the chip from the output side, such side feedback can fine tune the current in real time, thus improving the accuracy of the output current. The device descriptions in the implementation diagram are shown in Table 1. 
Table1. The device descriptions in the implementation diagram

\begin{tabular}{|c|c|c|}
\hline Name & Function & $\begin{array}{l}\text { Reference } \\
\text { value }\end{array}$ \\
\hline $\mathrm{AC}$ & $\begin{array}{l}\text { An } \mathrm{AC} \text { power supply is provided that affects the output of the } \\
\text { rectifier bridge }\end{array}$ & $85-265 \mathrm{~V}$ \\
\hline $\mathrm{C}_{1}$ & Filter capacitor, used to filter & $4.7 \mu \mathrm{F}$ \\
\hline $\mathrm{R}_{4}$ & For the VDD end of PT4201, buck is used & $1.5 \mathrm{M} \Omega$ \\
\hline $\begin{array}{l}\text { R1、C3、 } \\
\text { VD2 }\end{array}$ & $\begin{array}{l}\text { A RCD absorption loop used to absorb spikes generated by an Q1 } \\
\text { switch }\end{array}$ & $\begin{array}{l}220 \mathrm{k} \quad \Omega \\
2200 \mathrm{pF}\end{array}$ \\
\hline $\mathrm{R}_{7}$ & Used to set the switching frequency & $100 \mathrm{k} \Omega$ \\
\hline $\mathrm{R}_{9}$ & Used for sampling and setting current & $200 \Omega$ \\
\hline $\mathrm{R}_{3}$ & Current limiting resistor & $100 \Omega$ \\
\hline $\mathrm{VD}_{4}$ & $\begin{array}{l}\text { It is a regulator tube, a rectifier limit pressure role, when working } \\
\text { without load }\end{array}$ & $12 \mathrm{~V}$ \\
\hline $\mathrm{R}_{2}$ & $\begin{array}{l}\text { It is a shunt resistor, the current flowing through the } \mathrm{R} 2 \text { is } 10 \mathrm{~mA} \text {, and } \\
\text { the voltage at the left of the } \mathrm{R} 2 \text { is } 1 \mathrm{~V} \text {. }\end{array}$ & $200 \Omega$ \\
\hline $\mathrm{R}_{6}$ & $\begin{array}{l}\text { The voltage at both ends is about } 1 \mathrm{~V} \text {, and the output current is } \\
\text { regulated by selecting the resistance value }\end{array}$ & $3.3 \Omega$ \\
\hline
\end{tabular}

The design is based on PT4201 offline semiconductor lighting driver applications, PT4201 is a high brightness LED drive controller that works in current mode and can drive $1 \mathrm{~W}$ to $30 \mathrm{~W}$ lighting or spotlights. The high brightness LED drive system with isolated optocoupler feedback based on PT4201 has the advantages of constant current accuracy, simple peripheral circuit, no flicker and low EMI radiation. This design idea is very convenient for students to improve their design and practice ability.

\section{Facing the Application, and Cultivating the Innovation Consciousness and Ability}

The innovative education is an important content in cultivating college students, and it also is an effective method for college students to improve their own knowledge literacy. Cultivating students' ability to analyze and solve problems independently and cultivating the applied talents are the fundamental goals in education[9]. The training of strengthening students' innovative thinking ability is the key to cultivate students' creative consciousness and innovation ability, which includes training of students' imagination, the reverse thinking, the non-logical thinking, the three-dimensional thinking, the comprehensive thinking and so on. At present, the practical teaching contents which are facing to the application mainly include the curriculum design, the innovation practice projects of students' science and technology, teacher researching projects, and the design project in the organization of the electronic design games, which have a certain engineering practical value in the design practice projects. The purpose of the application-oriented experimental teaching is to dig students' independent thinking abilities and innovative abilities, and at the same time, the teaching is a good opportunity to show students' innovative abilities.

\section{Acknowledgments}

This research was financially supported by Key scientific research projects of Jiangxi Provincial Department of Education (Grant NO. GJJ161218). Nanchang institute of technology research 
start-up funding.

\section{Conclusion}

The innovation education is an important content to cultivate college students, and it also is an effective way for college students to improve their comprehensive quality. In particular, the study-oriented universities should strengthen the innovative education and should make contribute to the goal in enhancing the independent innovation abilities and building an innovation-oriented country. Students can really have the innovative sense and the innovative ability, and they can be the builders of the innovative spirit.

\section{References}

[1] Cui Dong, Guo Yongxin. Application on EDA simulation technology among the analog electronic technology teaching[J]. China Science and Technology Information .2013 (5): 208-209.

[2] Wang Ziting, Wu Rong and other people. EDA technology and application [M]. Lanzhou: Lanzhou University Press .2013.

[3]H. van der Broeck, G. Sauerlander, M. Wendt. Power Driver Topologies and Control Schemes for LEDs. IEEE Applied Power Electronics Conference, Anaheim, 2007，31(5):319-325

[4] B. Wang, X. Ruan, K. Yao. A Method of Reducing the Peak-to-Average Ratio of LED Current for Electrolytic Capacitor-Less AC-DC Drivers. IEEE Transactions on Power Electronics, 2010, 25(3): 592-601

[5]Zhu Qingshi. Taking value of innovative quality and cultivating successful innovative talents [J]. China Higher Education. 2010 (01): 81-84.

[6] Xiong Wei, Hou missionary and other people. Circuit design of Multisim 7and simulation application on Multisim 7 [M]. Beijing: Tsinghua University Press .2009.

[7] Lin Wei, Huixi Liao, Ganhong Yi. Application of power electronic technology in power system[J]. Digital technology and Applications. 2012.10.15.

[8] Yan Song. Research on teaching model of analog electronic technology based on project driven[J]. China Science and technology information. 2013.5.1.

[9] Xingang Wang. Research on route and strategy of independent innovation of electronic technology in China[D]. Harbin university of science and Engineering, 2014.6.1.

[10] Xuecheng Zhang. Reform and innovation of digital electronic technology experiment[J]. Laboratory research and exploration, 2013.8.15. 